\title{
Stress Loading From Viscous Flow in the Lower Crust and Triggering of Aftershocks Following the 1994 Northridge, California, Earthquake
}

\author{
Jishu Deng \\ Seismological Laboratory, California Institute of Technology, Pasadena, California
}

Kenneth Hudnut

US Geological Survey, Pasadena, California

Michael Gurnis and Egill Hauksson

Seismological Laboratory, California Institute of Technology, Pasadena, California

\begin{abstract}
Following the $M_{w} 6.7$ Northridge earthquake, significant postseismic displacements were resolved with GPS. Using a three-dimensional viscoelastic model, we suggest that this deformation is mainly driven by viscous flow in the lower crust. Such flow can transfer stress to the upper crust and load the rupture zone of the main shock at a decaying rate. Most aftershocks within the rupture zone, especially those that occurred after the first several weeks of the main shock, may have been triggered by continuous stress loading from viscous flow. The long-term decay time of aftershocks (about 2 years) approximately matches the decay of viscoelastic loading, and thus is controlled by the viscosity of the lower crust. Our model provides a physical interpretation of the observed correlation between aftershock decay rate and surface heat flow.
\end{abstract}

\section{Introduction}

Major earthquakes are followed by aftershocks that occur at decreasing rates for months or even years. To maintain a high level of aftershock activity long after a major earthquake, several mechanisms could be involved in the postseismic process. Laboratory experiments suggest that both the frictional strength of a loaded fault [Dieterich, 1994] and the strength of fault zone materials [Scholz, 1968] could change with time. It has also been proposed that the reequilibration of pore fluid pressure could change the normal stress and contribute to the generation of aftershocks [Nur and Booker, 1972].

Another important but overlooked mechanism is the time-dependent shear stress loading in the source region. Geodetic data can potentially constrain this kind of stress loading following large earthquakes. Typically, broad-scale postseismic deformation has been attributed to viscoelastic relaxation below the seismogenic zone [e.g., Thatcher and Rundle, 1984]. The relaxation of the deviatoric stress in the lower part of the crust can transfer stress up to the upper crust and trigger aftershocks in the long term [e.g., Freed

Copyright 1999 by the American Geophysical Union.

Paper number 1999 GL010496.

0094-8276/99/1999GL010496\$05.00 and Lin, 1998]. Postseismic deformation data can constrain this gradual loading process which may be responsible for the time-dependent triggering of aftershocks.

The $M_{w}$ 6.7 Northridge, California, earthquake is a key event for helping us to understand this problem. In this paper we combine the extensive seismic and geodetic measurements with a realistic computer model of viscoelastic processes to explain the temporal decay and spatial patterns of aftershocks.

\section{Data}

Following the January 17, 1994 Northridge earthquake, significant postseismic deformation was observed at more than a dozen Global Positioning System (GPS) stations [Donnellan and Lyzenga, 1998; Heflin et al., 1998; Savage et al., 1998]. We adjusted the reference frames of Donnellan and Lyzenga [1998], Savage et al. [1998], and Shen et al. [1996] to match the base frame of the second release of the southern California velocity field by Southern California Earthquake Center (SCEC) using shared stations in the far field. We removed the interseismic signal from the total displacements by subtracting the value interpolated from Shen et al. [1996]. Figure 1A shows the postseismic displacements of the Northridge earthquake for a period of 2.9 years following the event. The deformation involves about 20 to $40 \mathrm{~mm}$ of NE-SW shortening and NW-SE elongation.

\section{Model}

Our model consists of both elastic and linear Maxwell viscoelastic materials with a free-surface on top and a heterogeneous fault surface embedded in a 3-D Cartesian space. An elastic upper crust overlies a weak lower crust between 16.7 and $30.0 \mathrm{~km}$ and a stronger upper mantle below 30 $\mathrm{km}$. The boundary between the elastic upper crust and the viscoelastic lower crust is determined from the depth of the $95 \%$ cutoff of aftershocks. The Moho depth was inferred from the crustal thickness map constrained by the observed Moho-reflected $P m P$ phase [Richards-Dinger and Shearer, 1997]. The viscosities of the lower crust and upper mantle are $1.0 \times 10^{18}$ and $1.0 \times 10^{20} \mathrm{~Pa} \mathrm{~s}$, respectively. The shear modulus is $3.0 \times 10^{10} \mathrm{~Pa}$, and Poisson's ratio is 0.25 for the whole volume considered. The force of gravity is not in- 

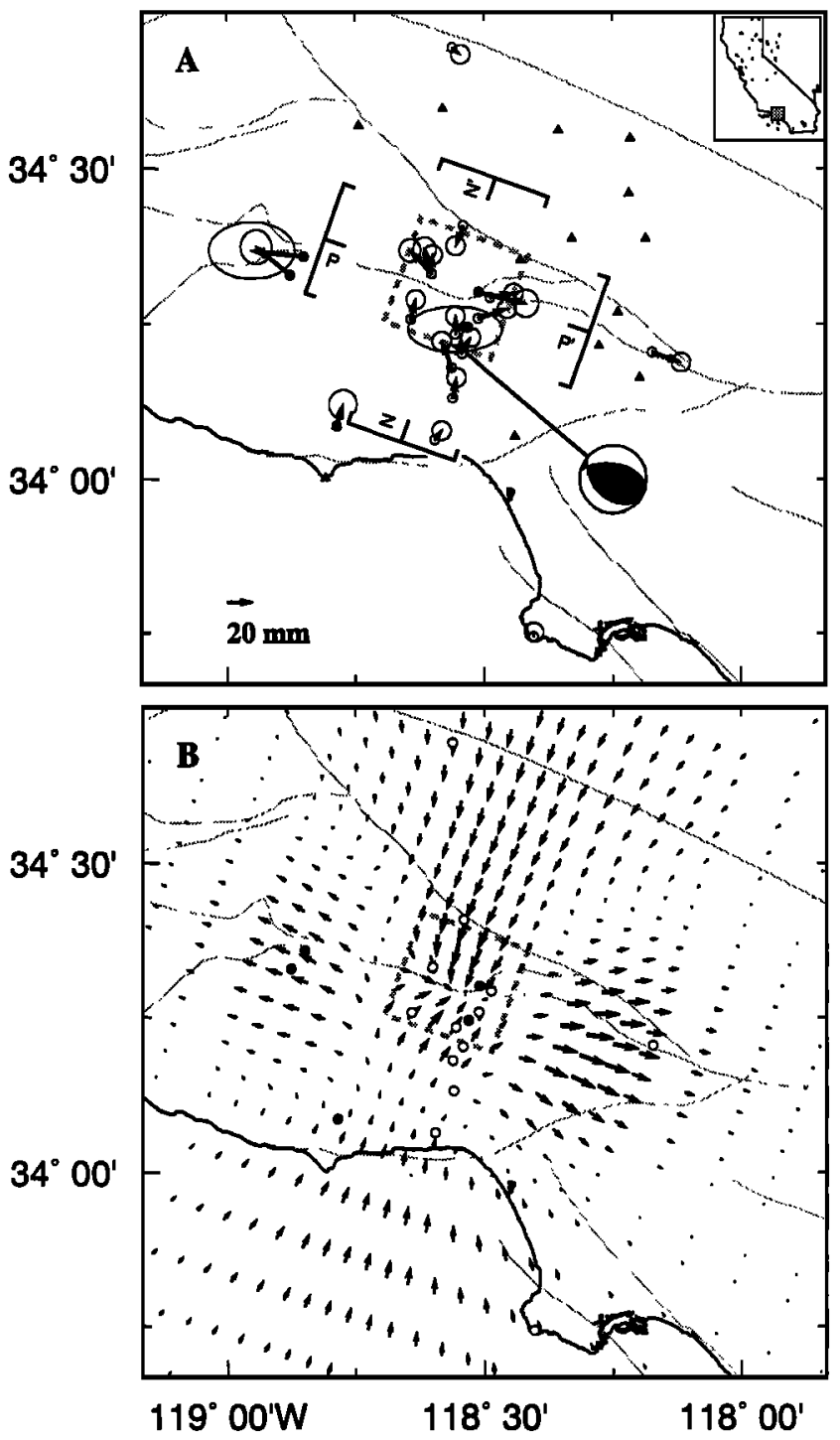

Figure 1. (a). Postseismic displacements following the 1994 Northridge earthquake for a period of 2.9 years. Open and sclid circles represent stations of Savage et al. [1998] and Donnellan and Lyzenga [1998], respectively. Pre-Northridge level of interseismic deformation have been removed using measurements from Shen et al. [1996] (triangles). Ellipses are 1- $\sigma$ uncertainties. Star and beachball show the epicenter and lower hemisphere focal mechanism of the main shock. Dashed box indicates the surface projection of the fault rupture. (b). Calculated postseismic displacements for the same period. The grid resolution close to the fault zone is higher than plotted.

cluded. An irregular $60 \times 50 \times 34$ finite element grid covering 600,600 , and $300 \mathrm{~km}$ in northeast, northwest, and vertical directions was constructed to compute the time-dependent stress, stress rates, and displacements. The resolution near the fault is $2 \times 2 \times 1.4 \mathrm{~km}$. The finite element code FEVER (Finite Element code for Visco-Elastic Rheology) [Deng, in preparation, 1999] is used to perform all coseismic and postseismic calculations.

The coseismic slip distribution of the fault is constrained from GPS and leveling measurements. We recalculated inversions for the displacements on 130 fault patches (10 along-strike by 13 down-dip) using data from Hodgkinson et al. [1996] and Hudnut et al. [1996].
Figure 1B shows the computed displacements over part of the computational zone for the same 2.9-year period after the earthquake as bounded by theGPS data. The general pattern of NE-SW shortening and NW-SE elongation is well explained by the viscoelastic model, indicating that viscoelastic relaxation in the lower crust could be an important mechanism controlling the postseismic deformation. The purely viscoelastic model is inadequate to explain observations at several stations immediately above the rupture zone. Some secondary, localized processes such as poroelastic rebound [Bosl and Nur, 1997] or shallow aseismic slip in the rupture zone [Donnellan and Lyzenga, 1998] may be involved.

Both coseismic and postseismic processes perturb the stress field significantly. Figure 2 illustrates the coseismic and postseismic displacement field and changes in shear stress for cross-section NN' in Figure 1A. The stress is resolved for faults with strike $110^{\circ}$, dip $50^{\circ}$, and rake $90^{\circ}$. Figure 3 is the same as Figure 2 but for cross-section PP'. The main shock creates a large, coseismic, stress shadow in the middle of the rupture zone and areas of stress enhancement near the fault tip as well as off the fault (Figures $2 \mathrm{~A}$ and $3 \mathrm{~A}$ ).

There is, however, a poor correlation between aftershocks and positive changes in coseismic stress (Figures 2A and 3A). If all events in our focal mechanism catalog are considered, only about $51 \%$ of events occurred where the calculated coseismic stress increased. Hardebeck et al. [1998] provides details on coseismic stress transfer following the Northridge earthquake.

Relaxation of the coseismic deviatoric stress in the lower crust generates a convection type of 3-D viscous flow, which pulls the fault zone down and transports material sidewards in the lower crust (Figures $2 \mathrm{~B}$ and $3 \mathrm{~B}$ ). The resulting pattern of stress is consistent with the majority of aftershocks (more than $70 \%$ ) which involve thrust or strike-slip focal mechanisms with their $\mathrm{P}$ axes in NE-SW direction and $\mathrm{T}$ axes either in the vertical or NW-SE directions [Thio and Kanamori, 1996]. The hypocenters of about $60 \%$ of the aftershocks correlate very well with the positive changes in stress transferred from relaxation of the lower crust (Figures $2 \mathrm{~B}$ and $3 \mathrm{~B}$ ), indicating that the effect of viscoelastic relaxation could have a first order influence on aftershock triggering. If we plot the total coseismic and postseismic change in stress, however, we can not find a good correlation between stress and occurrence of earthquakes. This might still indicate that the coseismic part in the fault zone is highly dependent on detailed slip distribution which is not well resolved.

While only about $14 \%$ of aftershocks are considered in Figures 2 and 3 , we find the same high level of correlation if all individual aftershocks in our focal mechanism catalog are included. Figure 4 shows the average stress loading rate of all aftershocks in our focal mechanism catalog binned into 30-day groups. In the first month following the main shock, about $59 \%$ of aftershocks occurred where the calculated shear stress loading rate is positive. After the first month, the percentage increased to $65 \%$. The viscoelastically driven stress loading and the rate of aftershock occurrence begin to decrease similarly with time after several months. The average loading rates for all earthquakes in our focal mechanism catalog in the first year or so is about 0.03 which is very significant for such a low slip-rate fault. 

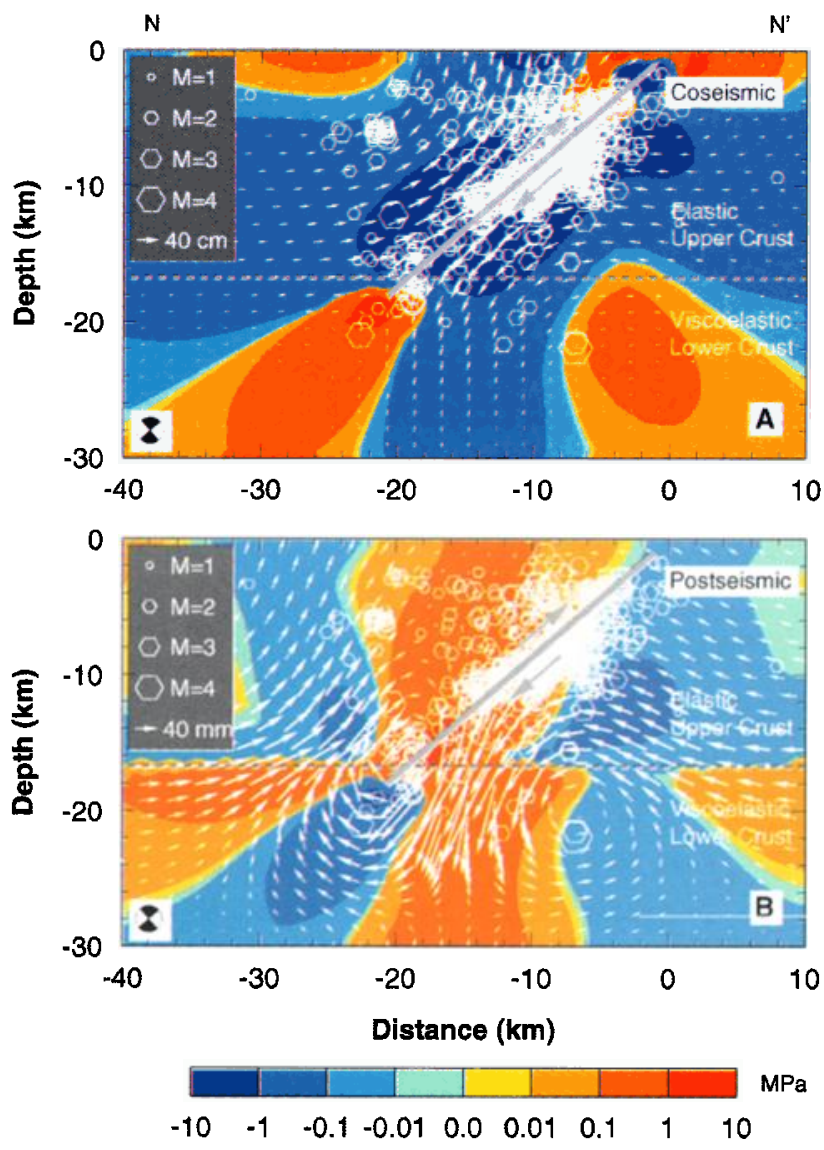

Figure 2. Cross section NN' (Figure 1a) showing coseismic (a) and postseismic (b) changes in shear stress resolved for faults with strike $110^{\circ}$, dip $50^{\circ}$, and rake $90^{\circ}$. Hexagons indicate aftershocks whose strike, dip, and rake differ from those of the shown mechanism by no more than $25^{\circ}$. Shaded line and arrows represent rupture trace and sense of motion of the main shock. Note that the length scales of the arrows change by a factor of 10 from a to $b$.

\section{Discussion}

We assume that the $12.3 \mathrm{~km}$-thick weak lower crust is primarily responsible for observed intermediate-scale deformation. The viscosity, $1.0 \times 10^{18} \mathrm{~Pa} \mathrm{~s}$, is chosen to best match the magnitude of displacements at intermediate scales. If a slightly larger viscosity is used, the deformation pattern in Figure 1 will be similar to that shown, but the displacements will be smaller. The calculations at the time scale of this study are not very sensitive to the viscosity of the uppermost mantle, as long as it is larger by at least one or two orders of magnitude than that of the lower crust.

Based on our calculations, we believe that the tail in the aftershock time distribution is controlled by the viscosity of the lower crust. An important implication of our hypothesis is that the sequence duration should be shorter in an area with a higher geotherm; a higher geotherm implies a weaker lower crust and faster viscous relaxation. Our model provides a physical interpretation of the observed correlation between aftershock decay rate and surface heat flow in southern California and Japan [Mogi, 1967; Kisslinger and Jones, 1991].
The decay of aftershocks in the first several weeks, however, appears to be too fast to be explained solely by stress loading from viscous relaxation in the lower crust. As mentioned earlier, those events might be caused by other mechanisms such as the frictional weakening of the fault area and fatigue effects of fault zone materials.

If we consider the change in normal stress, or Coulomb Failure Function [e.g., Stein et al., 1994; Harris and Simpson, 1996], the correlation between the occurrence of aftershocks and positive loading rate is weaker. This result suggests that the effects of changes in normal stress on aftershock triggering could be secondary.

\section{Conclusions}

We interpret the postseismic displacements following the $M_{w}$ 6.7 Northridge earthquake as resulting from viscous flow in the lower crust in response to the coseismic changes in stress. We find a high correlation between positive changes in shear stress related to the viscoelastic relaxation process and aftershocks. We conclude that viscoelastic relaxation in the lower crust has a first order effect on stress triggering of crustal aftershocks. Viscoelastic flow of the lower crust can explain not only geodetically observed postseismic deformation, but also the very gradual return to background seismicity rates after moderate to large earthquakes.
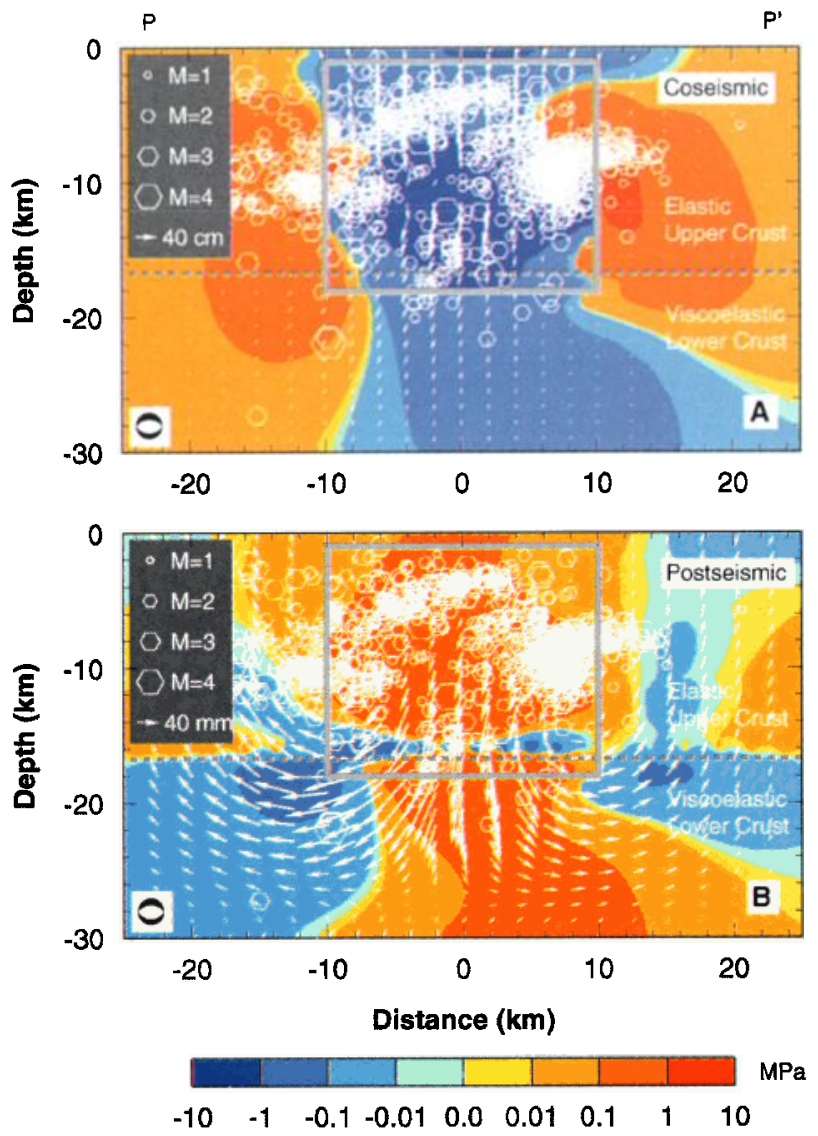

Figure 3. Same as Figure 2 but for cross section PP'. 


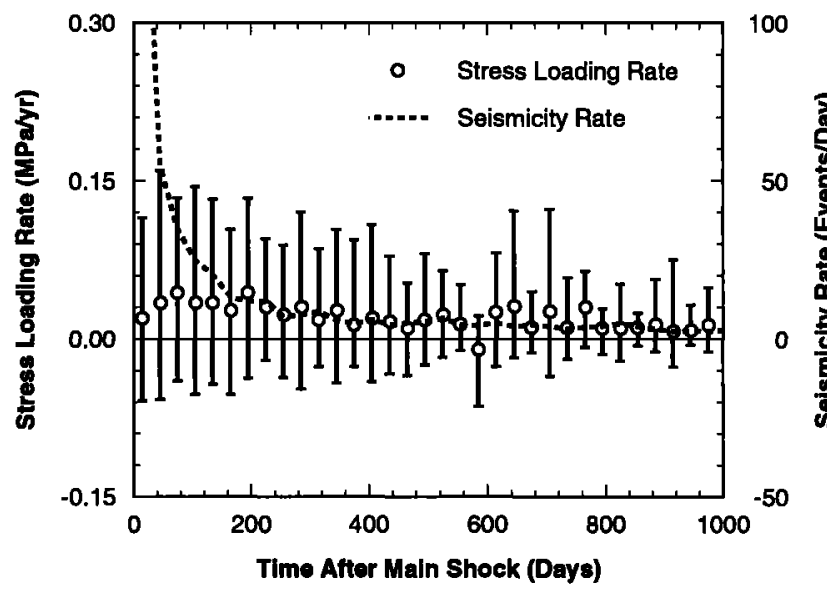

Figure 4. Average shear stress loading rate (open circles) for aftershocks in the focal mechanism catalog, and overall decay of all aftershocks in the Southern California Seismographic Network catalog. Events are grouped into every 30 days. Error bars indicate the upper and lower boundaries bracketing the central $80 \%$ events around the average.

Acknowledgments. This research was supported by the Southern California Earthquake Center. SCEC contribution 465. This also represents contribution number 8622 of the Division of Geological and Planetary Sciences, California Institute of Technology.

\section{References}

Bosl, W. J., and A. Nur, Numerical simulation of postseismic vertical displacement due to pore pressure changes following the 28 June 1992 Landers earthquake, Eos, Trans. $A G U 78$, F491,1997.

Dieterich, J., A constitutive law for rate of earthquake production and its application to earthquake clustering, J. Geophys. Res., 99, 2601-2618, 1994.

Donnellan, A., and G. Lyzenga, GPS observations of fault afterslip and upper crustal deformation following the Northridge earthquake, J. Geophys. Res., 103, 21,285-21,297, 1998.

Freed, A., and J. Lin, Time-dependent changes in failure stress following thrust earthquakes, J. Geophys. Res., 103, 24,393$24,409,1998$.

Hardebeck, J. L., J. J. Nazareth, and E. Hauksson, The static stress change triggering model: Constraints from two southern California aftershock sequences, J. Geophys. Res., 103, 24,42724,437, 1998 .
Harris, R. A, and R. W. Simpson, In the shadow of 1857-the effect of the great Ft. Tejon earthquake on subsequent earthquakes in southern California, Geophys. Res. Lett., 23, 229-232, 1996.

Heflin, M., et al., Rate change observed at JPLM after the Northridge earthquake, Geophys. Res. Lett., 25, 93-96, 1998.

Hodgkinson, K. M., R. S. Stein, K. W. Hudnut, J. Satalich, J. $\mathrm{H}$. Richards, Damage and restoration of geodetic infrastructure caused by the 1994 Northridge, California, earthquake, $U$. S. Geological Survey Open-File Report 96-517, 70 pp., Menlo Park, CA, 1996.

Hudnut, K. W., et al., Co-seismic displacements of the 1994 Northridge, California, earthquake, Bull. Seismol. Soc. Am., 86, S19-S36, 1996.

Kisslinger, C., and L. M. Jones, Properties of aftershock sequences in southern California, J. Geophys. Res., 96, 11,94711,958, 1991.

Mogi, K., Earthquakes and fractures, Tectonophysics, 5, 35-55, 1967.

Nur, A., and J. R. Booker, Aftershocks caused by pore fluid flow? Science, 175, 885-887, 1972.

Richards-Dinger, K. B., and P. M. Shearer, Estimating crustal thickness in southern California by stacking $P m P$ arrivals, $J$. Geophys. Res., 102, 15,211-15,224, 1997.

Savage, J. C., J. L. Svarc, W. H. Prescott, and K. W. Hudnut, Deformation following the 1994 Northridge earthquake $(M=6.7)$, southern California, Geophys. Res. Lett., 25, 2725-2728, 1998.

Scholz, C. H., Microfractures, aftershocks, and seismicity, Bull. Seismol. Soc. Am., 58, 1117-1130, 1968.

Shen, Z.-K., D. D. Jackson, and B. X. Ge, Crustal deformation across and beyond the Los Angeles basin from geodetic measurements, J. Geophys. Res., 101, 27,957-27,980, 1996.

Stein, R. S., G. C. P. King, and J. Lin, Stress triggering of the $1994 \mathrm{M}=6.7$ Northridge, California, Earthquake by its predecessors, Science, 265, 1432-1435, 1994.

Thatcher, W., and J. B. Rundle, A viscoelastic coupling model for the cyclic deformation due to periodically repeated earthquakes at subduction zones, J. Geophys. Res., 89, 7631-7640, 1984.

Thio, H. K., and H. Kanamori, Source complexity of the 1994 Northridge earthquake and its relation to aftershock mechanisms, Bull. Seismol. Soc. Am., 86, S84-S92, 1996.

J. Deng, M. Gurnis, and E. Hauksson, Seismological Laboratory 252-21, California Institute of Technology, Pasadena, CA 91125, USA (email: jishu@gps.caltech.edu; gurnis@caltech.edu; hauksson@gps.caltech.edu)

K. Hudnut, U.S. Geological Survey, 525 South Wilson Avenue, Pasadena, CA 91106, USA (e-mail: hudnut@gps.caltech.edu)

(Received April 14, 1999; revised June 14, 1999; accepted June 17, 1999.) 